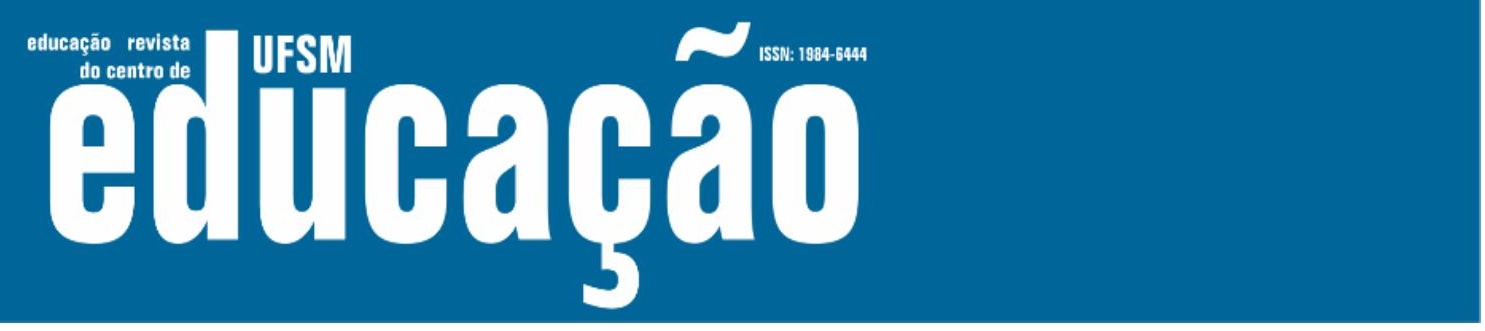

ISSN: 1984-6444 | http://dx.doi.org/10.5902/1984644443121

\title{
DoMi-BEBÊ: Instrumento de observação das expressões musicais de bebês e crianças pequenas em contextos de aprendizagem
}

\author{
DoMi-BEBÊ: Instrument for observing musical expressions of infant and \\ toddlers in learning contexts
}

Fabiana Leite Rabello Mariano

Professora doutora no Instituto Federal de São Paulo. São Paulo, São Paulo, Brasil.

fabianalrm@yahoo.com.br - https://orcid.org/0000-0003-3704-0383

Ricardo José Dourado Freire

Professor doutor na Universidade de Brasília. Distrito Federal, Brasília, Brasil.

freireri@gmail.com - https://orcid.org/0000-0003-3472-0279

Sandra Ferraz de Castilho Dourado Freire

Professora doutora associada na Universidade de Brasília. Distrito Federal, Brasília, Brasil. sandra.ferraz@gmail.com - https://orcid.org/0000-0002-6817-6358

Recebido em 25 de março de 2020

Aprovado em 17 de setembro de 2020

Publicado em 30 de setembro de 2021

\section{RESUMO}

O artigo apresenta resultados de pesquisa que teve por objetivo reelaborar e sistematizar um instrumento pedagógico para observação e acompanhamento das expressões musicais de bebês e crianças pequenas, denominado na atual versão: DoMi-bebê (Evidências do domínio musical dos bebês e crianças pequenas). A primeira versão foi elaborada para ser utilizada em contextos de aprendizagem musical embasadas na Teoria da Aprendizagem Musical (TAM), de Edwin Gordon. Assim, a proposta pode contribuir para 0 aprimoramento dos professores especializados em educação musical ou generalistas, relativamente à observação e reflexão sobre os aspectos musicais e interacionais presentes nos processos de aprendizagem musical inspirados pela TAM. Considera-se a avaliação como meio de promover a aprendizagem da criança, e para além, como parte de um processo que envolve aspectos como a qualidade dos ambientes, das propostas pedagógicas e da formação dos professores. Com isso, os resultados se referem à revisão e ampliação teórica que embasou a primeira versão do instrumento. A partir disso, foram analisadas e codificadas partes de três obras da Teoria da Aprendizagem Musical de Edwin Gordon. Dessa forma, com o apoio do programa de análise de conteúdo Atlas.TI8, foram estabelecidas categorias a partir desse corpo teórico, especificamente, sobre os tipos e estádios da Audiação Preparatória. Também 


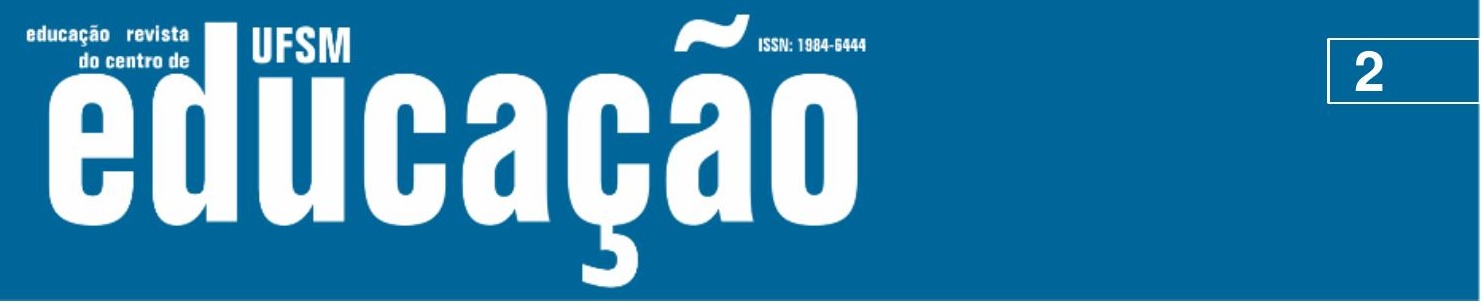

ISSN: 1984-6444 | http://dx.doi.org/10.5902/1984644443121

compõe o corpo teórico, relativamente às metodologias em participação, os processos da comunicação inicial nos bebês e a discussão sobre avaliação na educação infantil. As abordagens teóricas foram adequadas para estabelecer critérios e reestruturar o instrumento, sendo ainda prematuro confirmá-los, antes da sua avaliação empírica com o público-alvo, em observações diretas ou análise de vídeos, a ser realizada na próxima etapa do estudo.

Palavras-chave: Bebês; Desenvolvimento Musical; Avaliação.

\section{ABSTRACT}

This article presents the path of re-elaboration and description of a pedagogical instrument for the observation and to follow the musical expressions of infant and toddlers, named currently as DoMi-Bebê-Evidence of the musical domain of babies and young children. Its first version was designed to be used in musical learning contexts based on Edwin Gordon's Musical Learning Theory (MLT). The proposal aims to contribute to the improvement of teachers' practices, regarding observation and reflection on music aspects and social interactions within the processes of music learning. Evaluation is considered as a means of promoting children's learning, and beyond, as part of a process that involves aspects such as the quality of the environments, pedagogical proposals, and teacher training. The results refer to the theoretical review and expansion that supported the first version of the instrument. Three works by Edwin Gordon'sregarding Music Learning Theory (MLT), were analyzed and categorized using the content analysis program Atlas.TI8. Categories were established after theoretical body. Guides the restructuring of the instrument aspects of MLT, as well as of the processes of initial communication in toddlers and of evaluation in early childhood education, especially about the methodologies in participation. The theoretical approaches were adequate to establish criteria and restructure the instrument, and it is still premature to confirm them, before their empirical evaluation with the target audience, in direct observations or video analysis, to be carried out in the next stage of the study.

Keywords: Babies; Musical Development; Evaluation.

\section{RESUMEN}

El artículo presenta resultados de investigación que tuvo como objetivo reelaborar y sistematizar un instrumento pedagógico para la observación y acompañamiento de las expresiones musicales de bebés y niños pequeños denominado en la versión actual: DoMi-Bebê-Evidencia del dominio musical de bebés y niños pequeños. La primera versión fue diseñada para ser utilizada en contextos de aprendizaje musical basados en la Teoría del Aprendizaje Musical (TAM), de Edwin Gordon. La propuesta puede contribuir al perfeccionamiento de profesores especializados en educación musical o generalistas, en cuanto a la observación y reflexión sobre los aspectos 


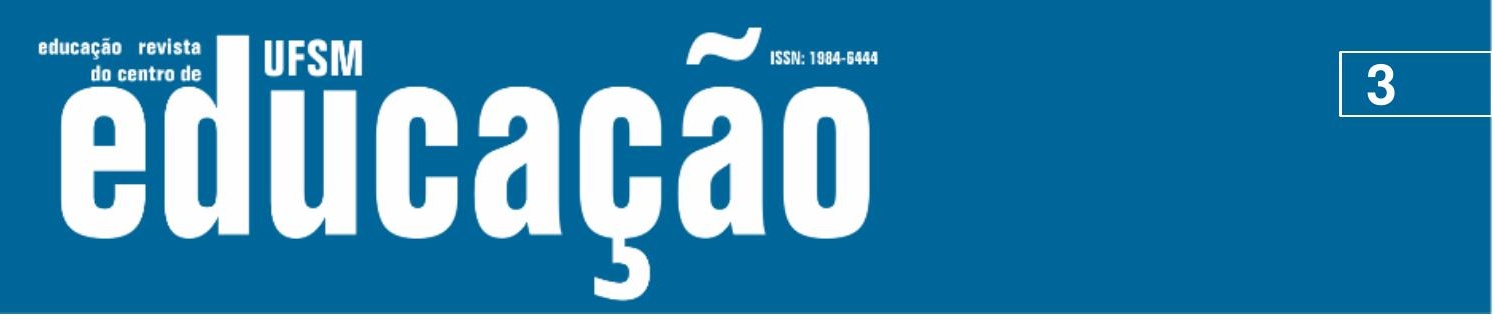

ISSN: 1984-6444 | http://dx.doi.org/10.5902/1984644443121

musicales e interacciones presentes en los procesos de aprendizaje musical inspirados en TAM. Se considera la evaluación un medio de promover el aprendizaje de los niños y niñas, y más allá, como parte de un proceso que involucra aspectos como la calidad de los ambientes, las propuestas pedagógicas y la formación docente. Los resultados se refieren a la revisión y expansión teórica que apoyó la primera versión del instrumento. Se analizaron y codificaron partes de tres obras de la Teoría del Aprendizaje Musical, de Edwin Gordon, con el apoyo del programa de análisis de contenido Atlas.TI8. Se establecieron categorías a partir de este cuerpo teórico, específicamente, en los tipos y etapas de la Audición Preparatoria. Por fin, conforman el cuerpo teórico los procesos de comunicación inicial en bebés y la discusión sobre la evaluación en la educación infantil, en cuanto a las metodologías en la participación. Los planteamientos teóricos resultaron adecuados para establecer criterios y reestructurar el instrumento, y aún es prematuro confirmarlos, antes de su evaluación empírica con el público objetivo, en observaciones directas o análisis de video, a realizarse en la siguiente etapa del estudio.

Palabras clave: Bebés, Desarrollo musical, Evaluación.

\section{Introdução}

Este artigo tem por propósito apresentar os resultados de um estudo desenvolvido no âmbito da avaliação da aprendizagem musical de bebês. Trata-se da sistematização de um instrumento pedagógico de observação de bebês e crianças pequenas no domínio da música. Denominado DoMi-Bebê (Evidências do domínio musical dos bebês e crianças pequenas), esse instrumento foi reelaborado a partir da primeira versão proposta por Mariano (2015), anteriormente destinado ao acompanhamento do impacto de uma intervenção pedagógica musical com um grupo de bebês de 0 a 18 meses de um berçário da rede pública.

Sua elaboração inicial foi inspirada em pressupostos da Teoria da Aprendizagem Musical (TAM), de Edwin Gordon (1999; 2000; 2013; 2015), e nos estudos sobre os comportamentos emocionais dos bebês de Fiamenghi (1999), adaptados anteriormente por Mariano e Fiamenghi (2009) para uso em contextos musicais. Esse instrumento foi utilizado em contexto de pesquisa onde observações relativas à TAM foram necessárias. Na nova versão, considera-se também os estudos sobre a musicalidade comunicativa de Malloch (1999-2000), Malloch e Trevarthen 


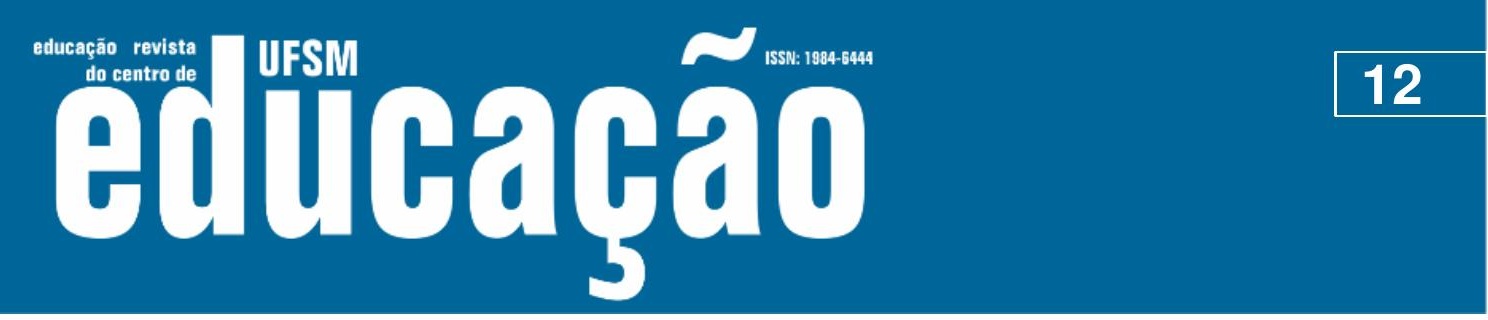

ISSN: 1984-6444 | http://dx.doi.org/10.5902/1984644443121

\section{Metodologia}

Apresenta-se um estudo exploratório, de abordagem dedutiva. Partiu-se da premissa que a Teoria da Aprendizagem Musical (TAM) traz informações descritivas suficientemente claras para subsidiar o/a professor/a para mapear e acompanhar o desenvolvimento musical dos bebês e crianças pequenas.

O estudo revisa e reelabora o instrumento desenvolvido por Mariano (2015) para um contexto de pesquisa em creches e berçários. Portanto, para a revisão desse protótipo, estabeleceu-se um diálogo com um projeto de musicalização para bebês e crianças pequenas que tem, em sua base pedagógica, a TAM. O estudo das demandas do ambiente musical e a análise do protótipo original, resultou em uma nova versão do instrumento, o qual será submetido à experimentação empírica. Ampliaram-se e adaptaram-se os critérios relativos aos comportamentos emocionais apresentados em contextos musicais propostos por Mariano e Fiamenghi (2009), bem como critérios oriundos da TAM.

A revisão de literatura possibilitou conhecer e contrapor as concepções de avaliação qualitativa na primeira infância, permitindo a reestruturação do instrumento alinhada a elas. Priorizaram-se, dentre as obras analisadas, aquelas que descrevem as evidências e detalha respostas para cada estágio da Audiação Preparatória na construção de novos critérios de observação que possam ampliar a caracterização dos tipos e estágios propostos por Gordon. A partir das obras analisadas, estabeleceu-se um diálogo entre as expressões a serem observadas, as singularidades individuais e o contexto. Portanto, o estudo da literatura contribuiu para a reestruturação do instrumento, no sentido de ampliar o detalhamento de aspectos relevantes dos critérios, justificando assim, a sua divulgação e testagem.

\section{Procedimentos}

A revisão de literatura teve por objetivo analisar o modelo conceitual de Audiação Preparatória proposta por Edwin Gordon, com fins a revisão e reformulação dos critérios do novo instrumento para avaliação da aprendizagem musical de bebês e crianças pequenas. Foi realizado um levantamento e uma sistematização sobre as 


\section{N-Tis

ISSN: 1984-6444 | http://dx.doi.org/10.5902/1984644443121

preenchimento dos resultados. O cabeçalho do instrumento apresenta as informações gerais da criança, como idade, dia da observação, qual canção observada e nome do/a observador/a.

O instrumento também considera as observações e registros da família em um diário musical, com descrições sobre o contexto musical familiar. Esse diário contribui para que o/a professor/a ou pesquisador/a conheça os hábitos musicais da família e compreenda melhor o desenvolvimento da criança de maneira mais contextualizada, além de perceber $o$ alcance das atividades musicais por ele realizadas.

\section{Análises}

O instrumento é pensado para os dois primeiros tipos da Audiação Preparatória (GORDON, 2008; 2013): Período da Aculturação e Período da Imitação. Esses dois primeiros tipos foram considerados como duas grandes categorias e seus estágios, a saber: absorção; respostas aleatórias; respostas intencionais; abandono do ego e decifragem do código, foram considerados como subcategorias. Nessas categorias estão destacadas todas as referências conceituais encontradas nos textos.

Outra categoria estabelecida a partir da leitura dos textos selecionados, denominada Orientações para a prática, abarca todas as orientações relativas à aplicabilidade dos conceitos referidos acima nas práticas musicais que se orientam pela Teoria da Aprendizagem Musical. As referências codificadas para cada um dos períodos estão relacionadas no mapa conceitual apresentado na Figura 1, onde é possível observar as suas inter-relações entre cada um dos Tipos e Estágios: 


\section{Uism

ISSN: 1984-6444 | http://dx.doi.org/10.5902/1984644443121

Figura 1 - Relações entre as respostas dos Tipos Aculturação e Imitação na TAM

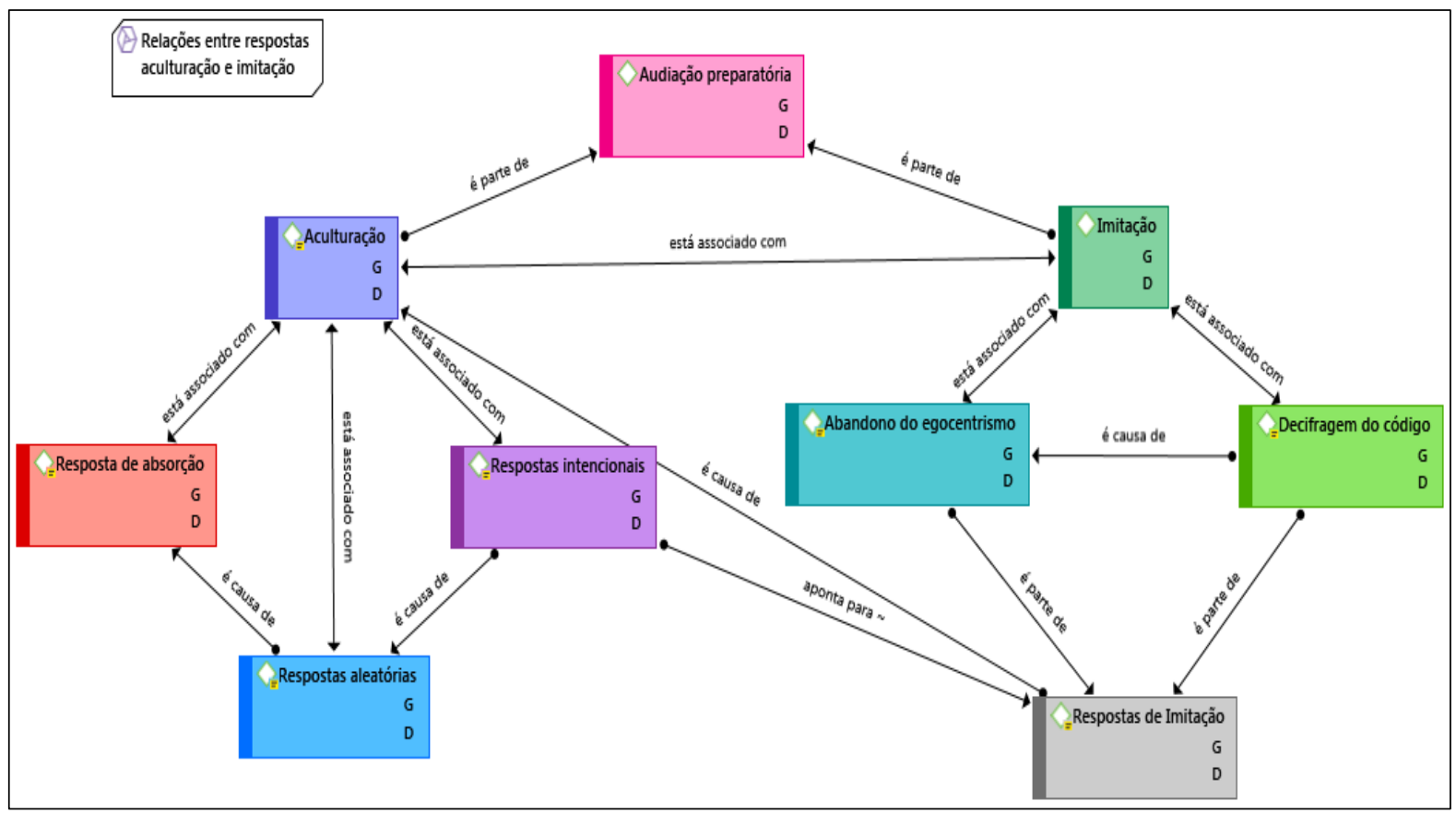

Fonte: Relações estabelecidas entre as respostas de aculturação e imitação. Desenvolvido no programa de análise de conteúdo Atlas.Ti8 (2020)

Por meio do mapa, é possível constatar as inter-relações entre cada um dos Tipos e Estágios do período. O período da Aculturação, que antecede ao período da Imitação, é decisivo para que as respostas das crianças relativas ao segundo tipo aflorem. É um processo gradual, interconectado e que demanda intervenções específicas para que a audiação preparatória se desenvolva. Os estágios possuem uma relação de causalidade, o que quer dizer que as crianças aos poucos darão indícios de que estão caminhando para um novo tipo de interação e de respostas aos estímulos musicais. Ao compreender esses sinais, o/a professor/a pode desenvolver mediações mais pontuais junto às crianças.

O primeiro Tipo, a Aculturação, em especial seu primeiro estágio, a Absorção, talvez seja o mais difícil de ser percebido, pois este, de forma geral, quando vinculado aos bebês, demanda um refinamento da observação por parte do adulto. Muitas vezes o bebê é muito responsivo ao canto contingente (CARVALHO et al, 2019), ou seja, um canto que presume uma interação e que pode desde muito cedo já produzir 


\section{Hism

ISSN: 1984-6444 | http://dx.doi.org/10.5902/1984644443121

respostas no sentido de uma intencionalidade comunicativa (MALLOCH, 1999-2000). É fato que sempre que se entra em contato com algo novo, a tendência é, em um primeiro momento, manter-se atento. Portanto, esse comportamento irá ocorrer nos processos de aprendizagem ao longo da vida, sempre que algo, absolutamente novo, acontecer.

É importante pontuar que as habilidades melódicas e rítmicas não caminham pareadas, ao contrário, são habilidades distintas e devido a isso podem se manifestar cada uma a seu tempo (GORDON, 2000; 2013; 2015). Por isso, o instrumento DoMiBebê propõe uma observação de cada uma das habilidades separadamente, como pode ser observado nos exemplos do Quadro 1, referente ao âmbito das respostas rítmicas aos estímulos melódicos, e no Quadro 2, referente ao âmbito das respostas melódicas aos estímulos rítmicos.

Quadro 1 - Respostas por movimentos corporais durante o canto melódico

\section{CAPACIDADES E HABILIDADES MELÓDICAS OBSERVADAS NO CANTO MELÓDICO SEM PALAVRAS}

Respostas Multimodais a estímulos melódicos vocais

\begin{tabular}{|l|l|l|l|l|}
\hline & Por movimentos corporais & SIM & $\begin{array}{l}\text { NÃO } \\
\text { SE APLICA }\end{array}$ & OBSERVAÇÕES \\
\hline 1 & $\begin{array}{l}\text { Reage ao estímulo musical melódico } \\
\text { movimentando a parte superior do } \\
\text { corpo sem aparente } \\
\text { correspondência com o desenho } \\
\text { melódico ou rítmico da canção }\end{array}$ & $\begin{array}{l}\text { Mantém-se parada apenas } \\
\text { observando a atividade ou vira-se em } \\
\text { direção ao som }\end{array}$ & & \\
\hline
\end{tabular}

Fonte: Excerto do Instrumento DoMi- Bebê, referentes às respostas por movimentos corporais a estímulos melódicos vocais (2020) 


\section{F WEM eltiogato}

ISSN: 1984-6444 | http://dx.doi.org/10.5902/1984644443121

Os critérios preveem a observação de algumas ações específicas para os membros superiores ou inferiores, como pode ser observado no critério 1 do Quadro 1 , onde o objetivo desse detalhamento é identificar como a criança manifesta-se com o corpo durante as atividades musicais. Uma das orientações da TAM, é a realização de movimentos fluídos realizados com todo o corpo, por isso a observação desse tipo de expressão pode orientar as oportunidades de movimento oferecidas aos bebês e crianças pequenas dentro das suas capacidades e possibilidades.

Os critérios elaborados não conservam, necessariamente, as mesmas palavras ou frases. A título de exemplo, o critério 2: "Mantém-se parada apenas observando a atividade ou vira-se em direção ao som", foi elaborado a partir da indicação da TAM em Reynolds, et al (1998, p. 24): "Child Turns her head or looks toward music".

Quadro 2 - Respostas vocais durante o canto rítmico

\section{CAPACIDADES E HABILIDADES RÍTMICAS OBSERVADAS NO CANTO RÍTMICO SEM PALAVRAS}

Respostas Multimodais a estímulos rítmicos vocais

\begin{tabular}{|l|l|l|l|l|}
\hline & Por vocalizações & SIM & $\begin{array}{l}\text { NÃO } \\
\text { SE APLICA }\end{array}$ & OBSERVAÇÕES \\
\hline 1 & $\begin{array}{l}\text { Vocaliza qualquer som enquanto } \\
\text { ouve a execução da canção }\end{array}$ & $\begin{array}{l}\text { Entoa com alguma correspondência } \\
\text { rítmica e intencionalidade trechos da } \\
\text { canção rítmica }\end{array}$ & & \\
\hline
\end{tabular}

Fonte: Excerto do Instrumento DoMi- Bebê, referentes às respostas por vocalizações a estímulos rítmicos vocais (2020)

Os excertos presentes no Quadro 2 são exemplos de ações que as crianças possivelmente farão durante as atividades musicais. Como visto na revisão de literatura em Malloch (1999-2000; 2009); Malloch e Trevarthen (2009); Carvalho et al (2019); Trehub (2015) dentre outros, o bebê responde precocemente aos estímulos 


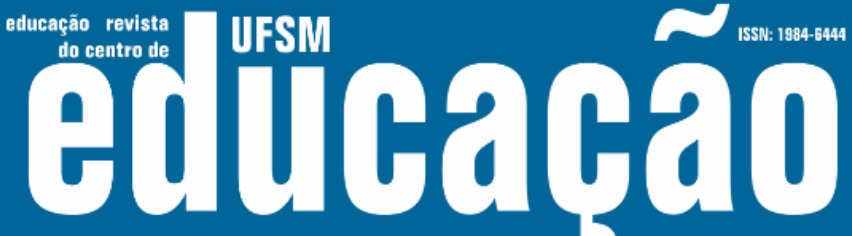 \\ 3}

ISSN: 1984-6444 | http://dx.doi.org/10.5902/1984644443121

Quadro 3 - Envolvimento durante o canto melódico ou rítmico

\section{ENVOLVIMENTO DURANTE O CANTO MELÓDICO SEM PALAVRAS}

\section{Canção melódica observada:}

\begin{tabular}{|l|l|l|l|l|l|l|}
\hline \multicolumn{2}{|l|}{ Engajamento ou desengajamento } & $\begin{array}{l}\text { Não } \\
\text { apresenta }\end{array}$ & $\begin{array}{l}\text { As } \\
\text { vezes }\end{array}$ & $\begin{array}{l}\text { Muitas } \\
\text { vezes }\end{array}$ & $\begin{array}{l}\text { Não } \\
\text { se } \\
\text { aplica }\end{array}$ & OBSERVAÇõES \\
\hline 1 & $\begin{array}{l}\text { Mantem-se atento no momento das } \\
\text { atividades melódicas com olhos } \\
\text { abertos ou boca entre aberta }\end{array}$ & & & & & \\
\hline 4 & Adormece durante a atividade & & & & \\
\hline
\end{tabular}

Fonte: Excerto do Instrumento DoMi- Bebê, referentes às respostas do Envolvimento: engajamento ou desengajamento a estímulos rítmicos ou melódicos vocais (2020)

Quadro 4 - Emoções durante o canto melódico ou rítmico

\begin{tabular}{|c|c|c|c|c|c|c|}
\hline \multicolumn{2}{|c|}{ Emoções } & \multirow{2}{*}{$\begin{array}{l}\text { Não } \\
\text { apresenta }\end{array}$} & \multirow{2}{*}{$\begin{array}{l}\text { As } \\
\text { vezes }\end{array}$} & \multirow{2}{*}{$\begin{array}{l}\text { Muitas } \\
\text { vezes }\end{array}$} & \multirow{2}{*}{$\begin{array}{l}\text { Não } \\
\text { se } \\
\text { aplica }\end{array}$} & \multirow[t]{2}{*}{ OBSERVAÇÕES } \\
\hline 2 & $\begin{array}{l}\text { Demonstra surpresa ao ouvir algum } \\
\text { som determinado ou ver algum } \\
\text { objeto musical arregalando os } \\
\text { olhos, levantando a sobrancelha, } \\
\text { emitindo algum som ou } \\
\text { movimentando-se }\end{array}$ & & & & & \\
\hline 3 & $\begin{array}{l}\text { Demonstra inquietação franzindo } \\
\text { sobrancelhas, fazendo caretas ou } \\
\text { resistindo à atividade }\end{array}$ & & & & & \\
\hline 4 & $\begin{array}{l}\text { Apresenta irritação chorando, } \\
\text { jogando objetos, agitando-se ou } \\
\text { gritando }\end{array}$ & & & & & \\
\hline
\end{tabular}

Fonte: Excerto do Instrumento DoMi- Bebê, referente aos critérios de observação para respostas do âmbito Envolvimento: emoções a estímulos rítmicos ou melódicos vocais (2020)

O critério 4 do Quadro 4, traz um exemplo de um excerto adaptado a partir dos critérios utilizados por Mariano e Fiamenghi (2011, p.144) para um contexto de intervenção musicoterapêutica. Na ocasião foi descrito como: "começar a ficar irritado 


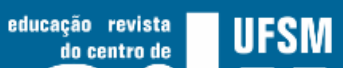 oltuarao

ou choroso; jogar os instrumentos, gritar manifestando negação à proposta", foi reelaborado como: "Apresenta irritação chorando, jogando objetos, agitando-se ou gritando". Na reelaboração do novo critério, procurou-se esclarecer a vinculação entre as ações de chorar, jogar, agitar-se ou gritar com o tipo de emoção: irritação.

A título de exemplo, se um bebê sempre apresenta irritação quando participa de uma determinada atividade musical, como sugerido no critério 4 do âmbito das emoções, descrito no Quadro 4, poderá ser investigado com mais atenção o que ocorre com a criança no intuito de se compreender os motivos do comportamento apresentado. A ocorrência dessa manifestação pode ser pontual, somente naquele dia, ou também pode ser uma resposta frequente àquela música, som ou tipo de interação. Também é possível que o comportamento de irritação da criança tenha sido em protesto à mudança da canção anterior para outra, ou à mudança na interação que havia sido estabelecida anteriormente. Ciente disso, o/a professor/a poderá diminuir o tempo de execução da canção, ou trocá-la e observar o que ocorre, e até mesmo modificar a forma de apresentá-la ou interagir, ou seja, experimentar novas formas de abordagem musical e interpessoal em decorrência da observação.

Sabe-se que quanto menor a idade da criança, mais complexa e sensível será a qualidade da atenção dispendida pelo/a professor/a para observar e interpretar as evidências dos seus desejos e necessidades, pois o foco se detém em conceder espaço ao protagonismo da criança.

Com vistas à análise final dos resultados, as informações observadas são agrupadas em uma tabela em separado, com campos para cada um dos âmbitos da avaliação realizada, como pode ser observado no Quadro 5. Nos campos relativos aos Tipos e Estágios da Audiação Preparatória, o/a observador/a deve marcar o número absoluto de ocorrências para cada um dos estágios - todas essas correlações estão descritas em um manual que acompanha o instrumento, contendo orientações sobre os procedimentos para o seu preenchimento. 


\section{工 WFM

Quadro 5 - Resultados

\section{RESULTADOS}

Indicação aproximada dos Tipos e dos Estágios observados

DATA

CAPACIDADES E HABILIDADES MELÓDICAS OBSERVADAS NO CANTO MELÓDICO SEM PALAVRAS

\begin{tabular}{|l|l|l|l|l|l|}
\hline $\begin{array}{l}\text { Respostas } \\
\text { Multimodais a } \\
\text { estímulos } \\
\text { melódicos vocais }\end{array}$ & \multicolumn{2}{|l|}{ TIPO ACULTURAÇÃO } & \multicolumn{2}{l|}{ TIPO IMITAÇÃO } \\
\cline { 2 - 6 } & Absorção & $\begin{array}{l}\text { Respostas } \\
\text { aleatórias }\end{array}$ & $\begin{array}{l}\text { Respostas } \\
\text { intencionais }\end{array}$ & $\begin{array}{l}\text { Abandono do } \\
\text { egocentrismo }\end{array}$ & $\begin{array}{l}\text { Decifragem } \\
\text { do código }\end{array}$ \\
\hline $\begin{array}{l}\text { Por movimentos } \\
\text { corporais }\end{array}$ & & & & & \\
\hline Por vocalizações & & & & & \\
\hline Pelo uso de objetos & & & & & \\
\hline TOTAL & & & & & \\
\hline
\end{tabular}

Fonte: Excerto do Instrumento DoMi- Bebê, referente aos Resultados e Relatório final (2020) (favor inserir $o$ ano que a tabela foi feita)

Ressalta-se que o relatório final é de cunho descritivo/qualitativo. Espera-se que seja realizada uma descrição minuciosa e objetiva, a partir de uma reflexão sensível, sobre o desenvolvimento da musicalidade da criança.

O último campo do Quadro 6, denominado de Relatório Descritivo Final, faz parte da tabela elaborada para registro dos resultados. Especificamente nesse campo, deve-se realizar por meio de uma narrativa as considerações sobre os resultados observados e que contemplem também as informações trazidas pelas famílias (parte da proposta do instrumento DoMi-Bebês). 


\section{Gutharão}

ISSN: 1984-6444 | http://dx.doi.org/10.5902/1984644443121

Quadro 6 - Relatório descritivo do Envolvimento e Relatório final

\begin{tabular}{|l|l|}
\hline $\begin{array}{l}\text { ENVOLVIMENTO NO CANTO RITMICO E } \\
\text { MELOODICO SEM PALAVRAS }\end{array}$ & $\begin{array}{l}\text { DESCREVA OS COMPORTAMENTOS COM } \\
\text { BASE NOS CRITÉRIOS OBSERVADOS }\end{array}$ \\
\hline $\begin{array}{l}\text { ENGAJAMENTO OU DESENGAJAMENTO } \\
\text { MELÓDICO }\end{array}$ & \\
\hline RITMICO & \\
\hline $\begin{array}{l}\text { EMOÇÕES } \\
\text { MELÓDICO }\end{array}$ & \\
\hline RITMICO & \\
\hline $\begin{array}{l}\text { INTERAÇÕES } \\
\text { MELÓDICO }\end{array}$ & \\
\hline RITMICO & \\
\hline PREFERÊNCIAS MUSICAIS & \\
\hline $\begin{array}{l}\text { RESULTADO DESCRITIVO FINAL } \\
\text { (Considerar as observações da família } \\
\text { sobre o contexto musical familiar) }\end{array}$ & \\
\hline
\end{tabular}

Fonte: Excerto do Instrumentol DoMi- Bebê, referente aos Resultados e Relatório final (2020)

A parte referente aos resultados e relatório final, possibilita uma observação ampliada de como os bebês e as crianças estão interagindo com o contexto musical proposto. Os resultados apresentados permitem o acompanhamento dos aspectos em que as crianças são mais responsivas, ou quais já foram alcançados, e a percepção de quais atividades e mediações são mais favoráveis para o processo. O relatório da família oferece a oportunidade para interação com a família, conhecer melhor os hábitos musicais da criança e como ela expressa a sua musicalidade e seus interesses no ambiente familiar, como visto na revisão de literatura, um paradigma da avaliação na Educação Infantil (FORMOSINHO, 2013).

Quando o/a professor/a estiver mais familiarizado/a com o uso do instrumento, poderá utilizá-lo de forma mais frequente, e assim tomar novas decisões ao longo do 


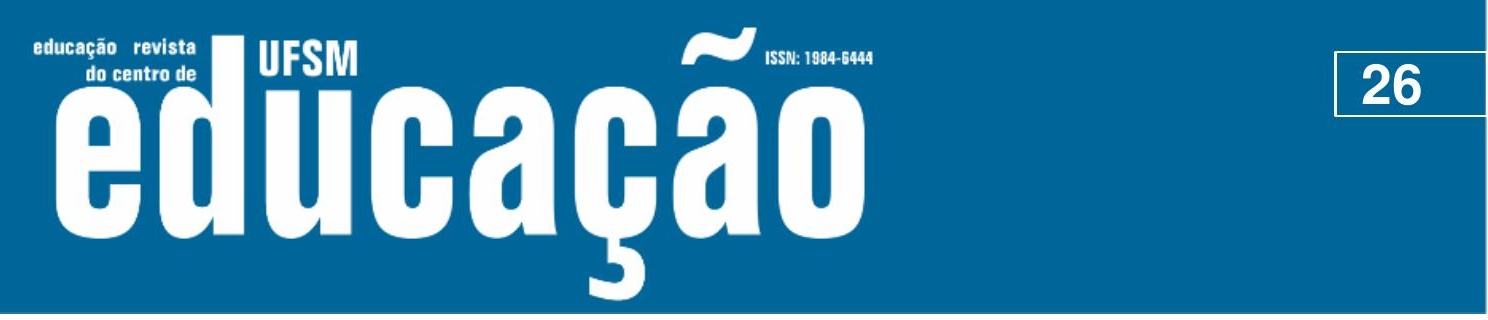

ISSN: 1984-6444 | http://dx.doi.org/10.5902/1984644443121

\section{Referências}

ANDRE, Aline Moreira. Tradução e validação da Escala Nordoff Robbins de Comunicabilidade Musical. Dissertação de Mestrado, Universidade Federal de Minas Gerais, Belo Horizonte, 2017.

CARVALHO, Maria Eduarda S; JUSTO, João M. R. M.; GRATIER, Maya; TOMÉ, Teresa; PEREIRA, Esmeralda; RODRIGUES, Helena. Vocal responsiveness of preterm infants to maternal infant-directed speaking and singing during skin-to-skin contact (Kangaroo Care) in the NICU. Infant Behavior and Development, v.57, Nov. 2019, p. 1-11. https://doi.org/10.1016/j.infbeh.2019.101332

CARVALHO, Maria Eduarda S. No olhar da voz maternal...A musicoterapia, o feto e o bebê. Forte da Casa: Climepsi Editores, 2019.

FIAMENGHI JR, Geraldo Antônio. Conversas dos Bebês. São Paulo: Hucitec, 1999.

FREIRE, Ricardo; FREIRE, Sandra. Towards a Theory of Music Instruction: a dialogue between Jerome Bruner and Edwin Gordon. Proceedings of International Society for Music Education - ISME's 29th World Conference, Beijing China, 2010. 1-6 ago.

FREIRE, GORDON, Edwin. Teoria da aprendizagem musical: competências, conteúdos e padrões. Lisboa: Fundação Calouste Gulbenkian, 2000.

GORDON, Edwin. Teoria da aprendizagem musical para recém-nascidos e crianças em idade pré-escolar. Lisboa: Fundação Calouste Gulbenkian, 2015.

GORDON, Edwin E. Music Learning Theory for Newborn and Young Children. Chicago: GIA Publication, 2013.

GORDON, Edwin; CAMERON, Charles. Guiding your child's music development. Chicago: GIA Publications, 1991.

ILARI, Beatriz S. Bebês também entendem de música: a percepção e a cognição musical no primeiro ano de vida. Revista da Abem, p.83-90, Set. 2002. Disponível em:

http://www.abemeducacaomusical.com.br/revistas/revistaABEM/index.php/revistaabe m/article/view/435 Acesso em: 01 Ago. 2019.

LAEVERS, Ferre. The Leuven Involvement Scale for Young Children. Belgica: Katholieke Universiteit Leuven, 1994.

LUCKESI, Cipriano Carlos. Avaliação da aprendizagem na educação infantil. INTERACÇõES. n. 32, p.191-201, 2014. Disponível em: https://doi.org/10.25755/int.6361 Acesso em: 10 Jan. 2020. 


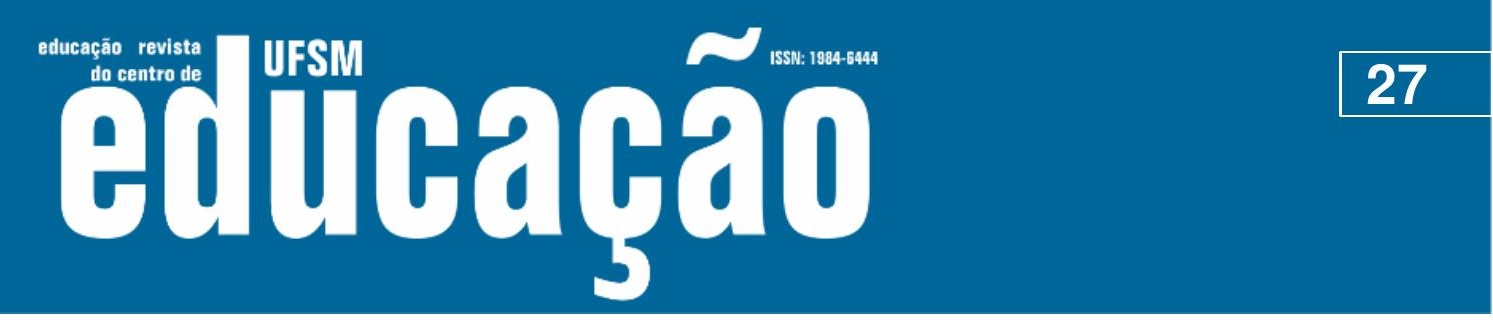

ISSN: 1984-6444 | http://dx.doi.org/10.5902/1984644443121

MALLOCH, Stephen. Mothers and infants and communicative musicality. Musicae Scientiae, v.3. , n. 1_suppl., p. 29-57, 1999, Disponível em: https://journals.sagepub.com/doi/10.1177/10298649000030S104 Acesso em: 01 Dez. 2019.

MALLOCH, Stephen, TREVARTHEN Colwyn. Communicative Musicality: Exploring the basis of human companionship. New York: Oxford University, 2009.

MARIANO, Fabiana Leite Rabello. Música no berçário: formação de professores e a teoria da aprendizagem musical de Edwin Gordon. 2015. Tese (Doutorado em Educação) - Faculdade de Educação, Universidade de São Paulo, São Paulo, 2015. doi:10.11606/T.48.2015.tde-14122015-153241. Acesso em: 01 Nov. 2019.

MARIANO, Fabiana Leite Rabello, FIAMENGHI JR, Geraldo Antônio. Avós/cuidadoras e seus netos com deficiência: uma experiência em musicoterapia. Aletheia, n. 34, p.138-150, Abril 2011. Disponível em: http://pepsic.bvsalud.org/scielo.php?script=sci_arttext\&pid=S1413-

03942011000100011. Acesso em: 20 dez. 2018.

MARSHAL, Herbert; BAILEY, Jennifer. Observing and Communicating Early Childhood Music and Movement Development. Perspective, v.4, n.2, 2009.

NAKATA, Takaiuki; TREHUB, Sandra. Infants' responsiveness to maternal speech and singing. Infant Behavior \& Development, v. 27. p. 455-464, 2004. Disponível em: https://doi.org/10.1016/j.infbeh.2004.03.002 Acesso em 01 dez.2019.

NIÉRI, Debora. Miniaturas Musicais: evidências do envolvimento de bebês com uma proposta sonoro-musical criativa. Orientador: Tisuko Morchida Kishimoto. 2018. Relatório (Pós-doutoramento) - Faculdade de Educação da Universidade de São Paulo, São Paulo, 2018. No prelo.

OLIVEIRA-FORMOSINHO, Júlia. Educação das crianças até aos três anos - algumas lições da investigação. In: Educação das crianças dos 0 aos 3 anos. 2010, Portugal. Actas do Seminário realizado no CNE em 18 de Novembro de 2010 [...]. Portugal: Conselho Nacional de Educação, 2011. Disponível em: https://www.cnedu.pt/pt/publicacoes/seminarios-e-coloquios/786-educacao-dascriancas-dos-0-aos-3-anos. Acesso em: 1 set. 2019.

OLIVEIRA-FORMOSINHO, Júlia. A avaliação Holística a avaliação na pedagogia-emparticipação. Interacções, v. 10, n. 32, p. 27 a 39, 2014. Disponível em: https://doi.org/10.25755/int.6346 https://doi.org/10.25755/int.6346 Acesso em: 01 Set. 2019.

OLIVEIRA-FORMOSINHO, Julia; FORMOSINHO, João. Pedagogia-emParticipação: A Perspectiva Educativa da Associação Criança. Porto: Porto Editora, 2013. 


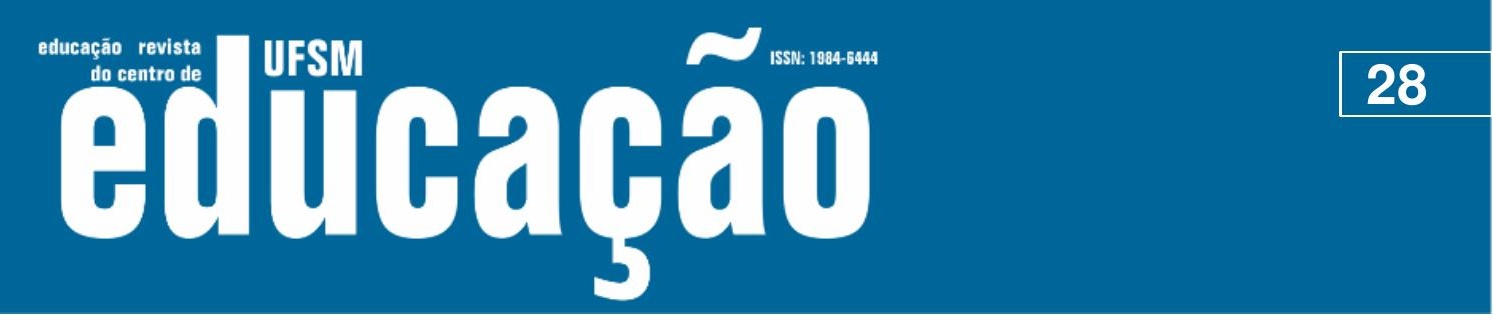

ISSN: 1984-6444 | http://dx.doi.org/10.5902/1984644443121

POLITIMOU, Nina; STEWART, Lauren; MÜLLENSIEFEN, Daniel; FRANCO, Fabia. Music@Home: A novel instrument to assess the home musical environment in the early years. PLoS ONE Public Library of Science, vol. 13(4), p. 1-23, April, 2018. Disponível em: https://doi.org/10.1371/journal.pone.0193819 Acesso em: 05 Jan. 2020.

REYNOLDS, Alisson et al. The Early Childhood Music Curriculum. Guide for parents, Teacher and Caregivers: Music Play. Chicago: GIA Publications, 1998. (Jump Right In).

SOUZA, Gizele de; BONDIOLI, Anna. Dossiê-Pesquisa em Avaliação de Contexto na Educação Infantil: compartilhamento de experiências Brasil e Itália. RELAdEI. Revista Latinoamericana de Educación Infantil, v. 6, n. 1-2, p. 17-22, 14 mar.2018. Disponível em: https://revistas.usc.es/index.php/reladei/article/view/4996. Acesso em 01 Mar. 2019.

STERN, Daniel. O mundo interpessoal do bebê: Uma visão a partir da psicanálise e da psicologia do desenvolvimento. Porto Alegre: Artes Médicas, 1992.

TORMIN, Malba Cunha. Dubabi Du: uma proposta de formação e intervenção musical na creche. 2014. Tese (Doutorado em Educação) - Faculdade de Educação, Universidade de São Paulo, São Paulo, 2014. Disponível em: https://teses.usp.br/teses/disponiveis/48/48134/tde-25092014-152305/pt-br.php। Acesso em: 10 jan. 2020.

TREHUB, Sandra; NAKATA, Takaiuki. Emotion and music in infancy. Musicae Scientiae, Special Issue, p.37-61, 2001-2002. Disponível em: https://journals.sagepub.com/doi/10.1177/10298649020050S103\.। Acesso em: 01 dez. 2018.

TREHUB, Sandra. Infant Musicality. In: HALLAM, S; CROSS, I; THAUT, M. The Oxford Handbook of Music Psychology (2 ed.). Oxford: Oxford University PressOnline Publication, Part 5, jan, 2015. Disponibilizado pela autora em: https://www.researchgate.net/publication/271907643_Infant_Musicality

TREHUB, Sandra.The developmental origins of musicality. Nature Neuroscience, v. 6; n.7, Jul. 2003. Disponível em: https://www.nature.com/articles/nn1084 Acesso em 01 set. 2019

VALERIO, Wendy $\mathrm{H}$. et al. Construct Validity of the Children's Music-Related Behavior Questionnaire. Journal of Research in Music Education, 2 ed. v.60, p. 186-200, 2012.

em: https://journals.sagepub.com/doi/abs/10.1177/0022429412444450 Acesso em: 10 jan. 2018. 


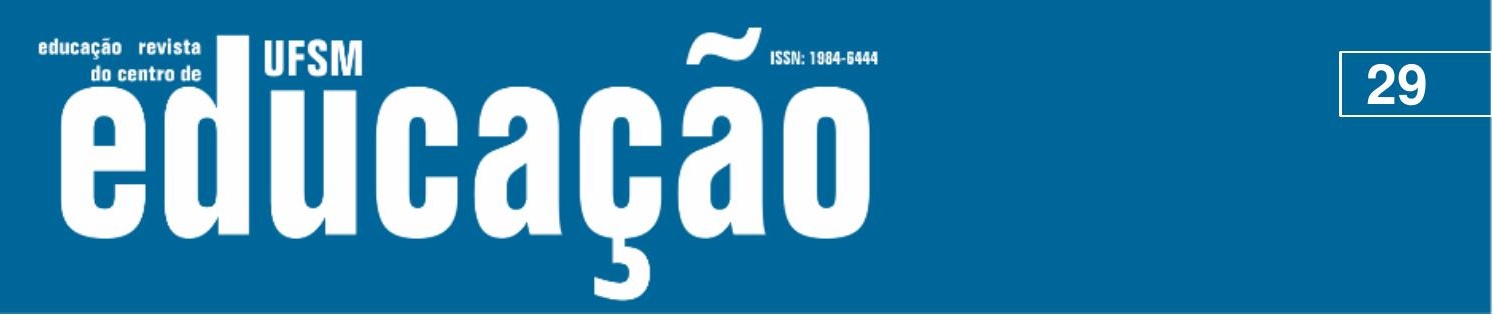

ISSN: 1984-6444 | http://dx.doi.org/10.5902/1984644443121

VALÉRIO, Wendy H. et al. Vocal Evidence of Toddler Music Syntax Acquisition: a case study. Bulletin of the Council for Research in Music Education, p. 33-45, Fall de 2006. Disponível em: https://www.jstor.org/stable/40319347?seq=1 Acesso em: 08 dez. 2019.

VIGOTSKY, Lev Semionovich. A construção do pensamento e da linguagem. $2^{a}$. Tradução: Paulo Bezerra. São Paulo: Martins Fontes, 2000.

VYGOTSKY, Lev Semionovich. Imaginação e criação na infância: ensaios psicológicos: livro para professores/Lev Semionovich Vygotsky. Apresentação e comentários Ana Luiza Smolka. Tradução: Zoia Prestes. São Paulo: Ática, 2009.

VIGOTSKY, Lev Semionovich. Obras Escolhidas. Vols. Tomos I, II, III. Madrid: Visor Y Ministério de Educación y Ciencia, 1930/1991.

ZABALZA, Miguel A.. Evaluar en Educación Infantil. RELAdEl. Revista Latinoamericana de Educación Infantil [en línea]. v. 6, n. 1-2, p. 9 -14. mar. 2018. ISSN 2255-0666. Disponível em: https://www.usc.gal/revistas/index.php/reladei/article/view/4995 Acesso em: 01 Set. 2019.

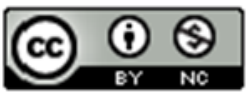

This work is licensed under a Creative Commons Attribution-NonCommercial 4.0 International (CC BY-NC 4.0)

\section{Notas}

\footnotetext{
1 Sólo la práctica reflexionada, revisada, evaluada, da conocimiento. La experiência sin más, solo da tablas y domínio de procedimentos

2 "ni se puede mejorar la calidad sin evaluación; ni tiene sentido la evaluación si no se orienta a la mejora de la calidad (ZABALZA, 2018, p.10).

${ }^{3}$ Although musicality, or the capacity for music, is a universal human trait with a biological basis (Trehub, 2003), cultural or experiential factors have a profound influence on the expression of that trait. (Trehub, p.7, 2015, p. 7)
} 